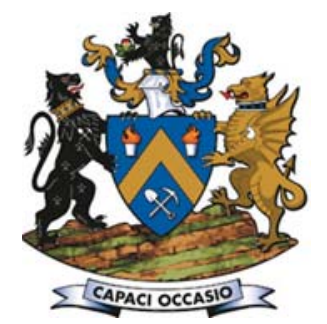

\title{
Impact of air granulation on the ferrochrome value chain in metallurgical smelter complexes
}

\author{
by F. Hannemann, M. Bradfield, M. Mahdi, L.L.C. So, and \\ D. Metcalfe
}

\section{Synopsis}

South African ferrochrome producers typically operate single tap-hole furnaces with alloy and slag separation occurring post-taphole by means of a skimmer block. Both streams are then cast directly onto a prepared surface, or in some cases a layer-casting process is employed using hot metal ladles. These processes all require significant cooling time followed by extensive in situ crushing operations, leading to a high burden and cost in terms of time and on-site material handling. Moreover, the slag is then further crushed and screened in a chrome recovery plant to liberate any entrained alloy, and subsequently discarded as waste.

Air granulation has achieved commercial success in other sectors and typical South African ferrochrome operations can also benefit. Air granulation promises lower production costs by elimination of casting, cooling, break-up, and crushing activities; improved alloy liberation by elimination of middlings; and improved safety due to faster cooling without water sprays. There is also a market for subsequent use of air-granulated ferrochrome slag as a valuable product, due to its potential improved physical properties over slow cooled variants.

Air granulation is being tested to evaluate its effect on the ferrochrome value chain within a typical South African metallurgical complex. Here we report the results of this first-of-its-kind work, and explore strategies for successful integration.

Keywords

slag handling, air granulation, dry granulation, energy recovery, granulation, ferroalloys, ferrochrome.

\section{Introduction}

Slag handling currently represents a significant safety, environmental, operational, and financial concern for ferroalloy production. Most smelters produce a slag-to-alloy mass ratio of 1.1 to 1.3 , therefore, slag handling and processing represents a significant part of typical operations. Slag handling differs by site based on environmental legislation, available space, and site location. The two most common slag handling processes are (1) air cooling and dry handling, which is by far the most common process in South African ferroalloy production, and (2) wet granulation in a highpressure water stream and wet handling.

\section{Slow cooling and dry handling}

In the majority of South African ferroalloy furnaces, metal and slag exit the same taphole. Two methods of separating metal and slag have historically been used, both relying on density differences: (1) transportation of slag using ladles or slag pots, and (2) a carbon block 'skimmer tapping arrangement' method, which is generally more labour-intensive but cheaper in terms of reduced equipment operating costs since ladles and hot metal cranes are not required. However, skimmer tapping can result in slag contamination of the metal. In both cases, slag is ultimately dumped or tapped onto the ground for initial slow cooling by natural air convection. Sometimes water sprays are also used to accelerate cooling; however, full solidification often requires several hours. Front end loaders or excavators are used to break up and extract the hot slag for transport to an open area before crushing. It typically takes several more days of cooling before the slag can be safely loaded into a crusher. Typically, crushing is completed by jaw crushing followed by cone crushing, after which the material is sent for density separation with pneumatic jigs and spirals

Dumping or tapping of liquid slag on the ground and subsequent slow cooling leads to various operational challenges. Firstly, the break-up and extraction by front end loaders or excavators is dangerous, because the initial cooling time allowed is often not enough for the slag to fully solidify, due to tapping frequency and tapping layout. Mobile equipment often handles the slag after only 2 to 3 hours because of the need for rapid turnaround in the tapping area, which means partially molten slag is handled. This poses dangers to both personnel and equipment, despite the use of specially modified mobile equipment for 'hot' environments, with replacement or maintenance costs being much

* Hatch Ltd, South Africa.

(C) The Southern African Institute of Mining and Metallurgy, 2018. ISSN 2225-6253. This paper was first presented at the INFACON XV: International Ferro-Alloys Congress, 25-28 February 2018, Century City Conference Centre and Hotel, Cape Town, South Africa 


\section{Impact of air granulation on the ferrochrome value chain in metallurgical smelter complexes}

higher than for conventional machines. Secondly, break-up and extraction of slag is time-consuming, and generates excessive amounts of dust. Spraying water into the slag pit is a common solution to accelerate cooling and reduce dust, but the potential for molten material/water explosions remains ever-present, and pooling of water can delay further tapping operations. Moreover, the water that is used is typically lost and increases plant water demand. Lastly, transportation of slow-cooled slag from the pit to downstream crushers and metal separators poses additional safety and operational risks. Transportation of semi-molten slag by mobile machinery requires dedicated roads, specialized equipment, and training. It also increases the area in which special precautions need to be taken to avoid contact between molten material and water. The repeated loading and transporting combined with crushing steps results in multiple dust sources and increased diesel consumption by mobile machinery.

\section{Water granulation}

Although not nearly as common in South Africa as dry slag handling, water granulation is used in a significant part of the industry globally. There are two major types of water granulation system: (1) at the end of the launder attached directly to the furnace, or (2) at a dedicated facility designed to accept slag pots or ladles. For safe and successful water granulation, it is critical to maintain the temperature, flow, and pressure of water in accordance with the temperature and flow of the molten material. The high-pressure water stream impacts the molten slag stream, breaking it apart to form small granules approximately $2 \mathrm{~mm}$ in diameter. The slag is rapidly solidified in the initial water blast and then cools further in a settling tank. Various options exist for slag dewatering and subsequent transfer to either a stockpile or a metal recovery plant.

There are significant operational, environmental, and safety challenges related to water granulation. Firstly, typical water granulation requires about $10 \mathrm{t}$ of water per ton of slag granulated, out of which roughly $1 \mathrm{t}$ of water is lost by evaporation. This has both environmental and financial implications, and in some areas makes the technology infeasible due to limitations on water consumption. The energy costs associated with pumping and cooling large volumes of water increase the operating cost of the process. Precautions are also required for the overall treatment and de-sludging of the water circuit to remove the build-up of deleterious metals and potentially harmful/toxic dissolved species. Further, the placement of the water granulation facility within the molten material zone of a furnace is hazardous, and requires special procedures for mitigating risks. If the facility is located directly in front of the furnace, control of molten material flowing through the tap-hole and into the water stream is critical. Therefore, continuous monitoring and maintenance of the tap-hole itself is extremely important.

\section{Dry granulation}

Both slow cooling and water granulation pose problems with safety, dust emission, energy consumption, environmental footprint, and cost - and there is value in implementing a new technology which addresses these problems. Dry slag granulation has been developed and commercialized over the past two decades with a focus on addressing the downfalls of traditional slag-handling methods. The three most common dry slag granulation categories are:

1. Mechanical granulation-Molten slag is broken up, dispersed, and quenched by mechanical means, such as rotating drums, blades (Bergquist, 1912; Metz, Schockmel, and Mersch, 1982; Orlander, Cotsworth, and MacKenzie, 1984; MacKenzie and Horvat, 1999, or shot material (Zhang et al., 2013; Fujii et al., 1982).

2. Centrifugal granulation-Molten slag is ejected radially outward by centrifugal force, during which it is broken up into small droplets, dispersed, and quenched into solidified granules. Examples include spinning disc and cups (Pickering et al., 1985; Maruoka et al., 2004; McDonald, 2013; Mizuoshi and Akiyama, 2003; Legille and Metz, 1979).

3. Air granulation-Air impinges on a molten slag flow, during which the slag is broken up into droplets, dispersed, and quenched into solidified granules. Compared to mechanical and centrifugal granulation, air granulation involves limited slag-to-machine contact, thus reducing the potential for equipment damage and failure, and the associated safety risks.

\section{Air granulation technology}

\section{State of the technology}

Hatch has successfully commercialized air granulation technology, which is currently implemented for slag handling at both ferrous (electric arc furnace, basic oxygen furnace, ladle furnace metallurgy) and non-ferrous (zinc and silicomanganese producers. In addition, a full-scale air granulation unit was commissioned in March 2018 for granulation of converter slag at a platinum group metals (PGM) facility in South Africa, serving as the first of its kind globally. Slag heat recovery is also possible and has been implemented at two commercial sites.

The major advantages of this technology include improved safety in slag handling (due to limited exposure of equipment and operators to hot molten slag, elimination of water and steam explosions), potential for slag heat recovery (via hot air for direct use or steam generation), production of higher value slag products with tunable properties (for example for use in abrasives, cement, or as aggregate), and reduction in the costs of slag handling (due to lower temperatures, lower maintenance requirements, and increased production uptime).

A schematic of air granulation technology is provided in Figure 1. Molten slag discharged from the furnace is conveyed to a slag feeding chute located in front of granulation chamber, either via slag launders or by slag pots/ladles. An air jet granulates, quenches, and disperses the slag into the granulation chamber, as shown in Figure 2. The air jet to slag mass ratio is in the range of 0.5 to 3 , and the air jet is at relatively low pressures of less than $20 \mathrm{kPa}$. Inside the chamber, the granulation blast air passes cocurrently to the hot granules to cool the particles and to obtain a hot gas stream. The cooled and solidified granules, shown in Figure 3, can be continuously conveyed out of the chamber to be packaged or periodically collected (for non- 


\section{Impact of air granulation on the ferrochrome value chain in metallurgical smelter complexes}

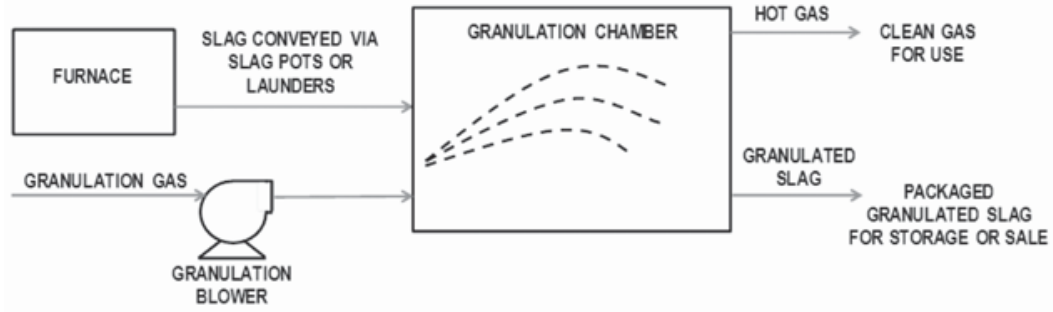

Figure 1 - Schematic process flow diagram of air granulation technology

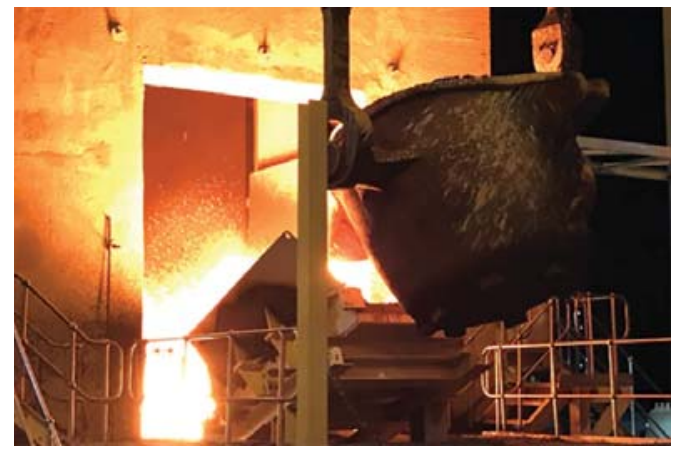

Figure 2-A current commercial application of air granulation technology

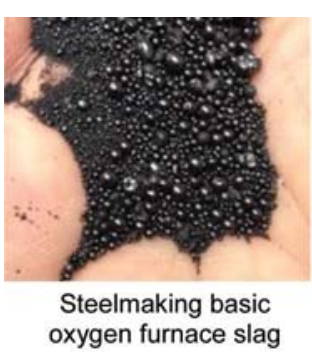

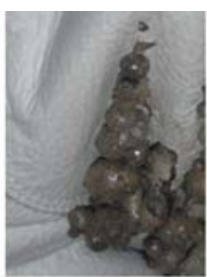

Silicomanganese slag

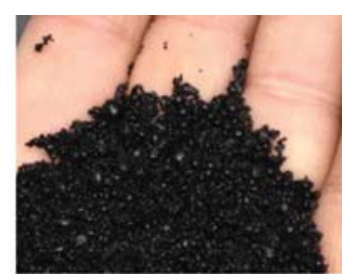

Zinc slag

Figure 3 - Air-granulated slags from commercial operations

continuous tapping operations) for classification by size, for storage, and/or for sale. The recovered hot exhaust gas is directed to equipment that uses this heat and/or an off-gas handling system.

\section{Air granulation technology for ferroalloy production}

\section{Potential benefits of air granulation technology for ferroalloy producers}

There are several motivations for exploring the use of air granulation technology for ferroalloy producers.

\section{Lower operating cost}

Slag treatment and handling constitutes an unavoidable but necessary cost in the production of ferro-alloys. The removal, treatment, and disposal of slag are considered a direct cost on the bottom line, with no expectation of revenue generation. Industries other than ferroalloys have successfully created a market into which all the slag produced is sold as a value- added product. This potential exists in the ferroalloy industry too, with crushed slag products already being used in downstream applications such as brickmaking. The creation of a viable revenue-generating slag product through air granulation would drastically enhance the viability and sustainability of a production complex by producing a second distinct revenue stream over and above alloy production.

\section{Environmental footprint}

Ferroalloy producers are now under increasing pressure not only to cease dumping of slag on-site, but also to remediate existing slag disposal sites and to provide a cleaner footprint. Global concerns for sustainability and resource consumption mean that ferroalloy producers need to reduce energy and water consumption, and utilize resources more efficiently while simultaneously decreasing their impact on the immediate environment. Water is becoming a more scarce commodity in South Africa and producers are being constrained in terms of access to water and enforcement of water-use licences. 


\section{Impact of air granulation on the ferrochrome value chain in metallurgical smelter complexes}

This means using less water in water granulation or switching to dry cooling, reducing or eliminating dust created by crushing and loading, as well as reducing transportation of materials to minimize diesel consumption. Furthermore, slag storage continues to represent a significant environmental legacy for plants that cannot convert slag into a usable product. Air granulation addresses all of these challenges while having the lowest capital and operating cost.

\section{Alloy liberation}

For recovery of entrained alloy droplets, the majority of ferroalloy production sites employ a dedicated chrome recovery sub-plant which utilizes density separation to extract remaining alloy from the slag prior to the long-term storage or sale of the slag material. The recovered metal tends to have a higher slag content than the furnace metal, and so is usually sold at a slight discount or recycled internally to casting beds or to the furnaces. The size distribution of the slag is critical to the metal recovery and grade obtained by this process. The recovery peaks in the 1$10 \mathrm{~mm}$ size range for most ferroalloy producers, although most plants will have a series of crushing steps. The larger size fraction has lower slag contamination and particles below $1 \mathrm{~mm}$ will typically exhibit metal recovery rates $10 \%$ less than other size fractions. Crushed slow-cooled slag has a wide particle size distribution, resulting in variable performance in the metal recovery plant as well, as throughput limitations depend on the design of the plant. Although water granulation provides a narrower size distribution, limitations are imposed by the temperature and flow rates of both slag and water as well as slag composition. Air granulation allows for improved tuning of particle size distribution, which could benefit alloy liberation and metal recovery in existing jigging processes

Air granulation also presents an additional potential benefit to the metal recovery circuit. In the granulation process, metal-rich slag particles may be separated from metal-poor slag particles (due to density differences, metalrich slag particles have a shorter flight path and land closer to the granulating air stream than metal-poor slag particles). The metal-rich slag particles can then be fed to the metal recovery circuit, thereby reducing the total tonnage of material processed by the metal recovery plant.

\section{Heat recovery}

The molten slag discharged from a metallurgical furnace constitutes a tremendous energy stream and, in some cases, can contain up to $80 \%$ of the total energy input to the process (Rodd et al., 2010). This energy represents a significant cost which is currently not recovered. In ground cooling, this energy is passively dissipated to the environment and is not reclaimed. In water granulation, energy recovery from hot water has been attempted on a pilot scale using several different technologies (Kotaro, Masahiko, and Tomoyuki, 1979; Kobe, Kakogawa, and Toyada, 1978; Kakogawa, 1982; Hooykas, 1979), but none of these have been commercialized due to the associated high costs and low quality of the heat source. Air granulation with slag heat recovery, on the other hand, has been found commercially viable in several facilities.

In discussions with producers, many saw the technological fit of air granulation within the ferrochrome sector. However, the lack of precedence in the ferroalloy industry and the lack of experimental data meant key questions were unanswered. These questions included:

(1) Is air granulation of ferrochrome slag technically feasible?

(2) Is the particle size distribution of air-granulated ferrochrome slag suitable and beneficial for metal recovery and/or alloy liberation?

(3) Are the physical and chemical properties of airgranulated ferrochrome slag suitable for its use in the desired market? More specifically, would air granulation stabilize the leachability of hexavalent chromium?

Testing of air granulation technology on ferrochrome slag was undertaken to answer such questions.

\section{On-site air granulation trials of ferrochrome slag}

To test the concept of air granulation of ferrochrome slags with minimal risk and cost, a laboratory-scale air granulation system was developed. This system consists of small-scale equipment that mimics the key design principles of the fullscale air granulation system, yet can be easily transported to site for testing. The system can granulate approximately $1 \mathrm{~kg}$ of slag per minute. Images of this portable system are shown in Figure 4. For this small system, a tapping operator uses sampling spoons to obtain slag samples directly from the settling furnace launder during normal operation, and then feeds the sample directly in front of an air nozzle blowing into a chamber. Production slags can be tested directly in situ to produce experimental samples on site under actual operating conditions.
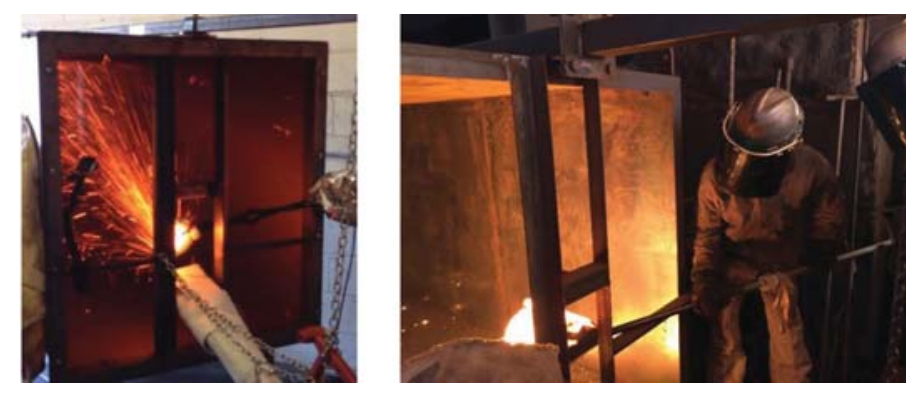

Figure 4-Laboratory-scale air granulation system used for on-site granulation of ferrochrome slag 


\section{Impact of air granulation on the ferrochrome value chain in metallurgical smelter complexes}

\section{Preliminary results}

Testing with laboratory-scale air granulation equipment was completed over a one-week period at a South African ferrochrome producer in 2017. The equipment comprised graphite sampling spoons, a blower, a nozzle, and a granulation chamber that was located alongside the tap-hole launder, near the tap-hole. Slag was sampled from the flowing slag stream immediately upstream of the skimmer block. Proximity to the launder was important to ensure that the small volumes of molten slag samples remained hot between sampling and pouring into the air stream.

\section{Technical feasibility}

Air granulation of ferrochrome slag is technically feasible despite the spoon-sampled slag cooling quickly - a limitation only of the laboratory-scale apparatus due to the low volume of the sample spoon. The quick cooling and limited superheat meant the slag had greater viscosity than material in other air granulation trials, which led to substantial volumes of solidified slag either remaining in the sampling spoon or falling and accumulating beneath the air stream.

Furthermore, a controlled flow of molten slag into the air stream was not achieved as large chunks of material caused flow surges, which means that quantification of key process parameters will require further testing. However, despite these challenges, preliminary observations indicate that the scaled-down process successfully granulated the molten slag into small particles, which at the full scale will be much simpler to handle and process for metal recovery. No smoke or dust was observed to emanate.

\section{Morphology and particle size distribution of air granulated slag}

Figure 5 shows images of the particles produced from the laboratory-scale air granulation trials. The particles ranged in size from approximately $1 \mathrm{~mm}$ to $50 \mathrm{~mm}$. The particles were dense and could not be crushed by hand. Larger particles of $>10 \mathrm{~mm}$ resembled crushed stone or aggregate. The particles greater than $10 \mathrm{~mm}$ can be attributed to quick-cooling slag being poured from the sampling spoon where it had solidified before passing through the air stream, therefore not being granulated. These larger particles are not representative of actual yield from air granulation and are artefacts of the laboratory-scale set-up. Smaller particles of $<10 \mathrm{~mm}$ were generally spherical. The shape and morphology of these particles were consistent with those from electric arc furnace and basic oxygen furnace steel slags, despite major differences in composition, temperature, and viscosity of the molten raw materials. The particle size distribution (PSD) of the $<10 \mathrm{~mm}$ particles was determined. The average PSD for five tests is shown in Figure 6 . The particles had an average particle size of approximately $6 \mathrm{~mm}$. The large variation in PSD between the five tests, shown by the error bars, is a result of the limited control of slag temperature, and therefore flow rate, when using the laboratory-scale set-up.

\section{Composition}

Granulated ferrochrome slag was collected from the chamber, as well as the non-granulated slag remaining in the spoon. This non-granulated slag was intended to be a baseline against which changes in composition resulting from air granulation could be determined, particularly relating to emissions and other forms of slag oxidation. Preliminary results indicate no compositional changes in the slag due to air granulation. This is in line with experience in steel and non-ferrous slag, wherein chemical compositional changes in slag resulting from air granulation are not observed.

\section{Cr(VI)}

To evaluate the chemical stability of the granulated slag, the leaching characteristics of the product, especially with regard to hexavalent chromium $(\mathrm{Cr}(\mathrm{VI}))$, will be investigated. A novel analytical technique is being developed to determine

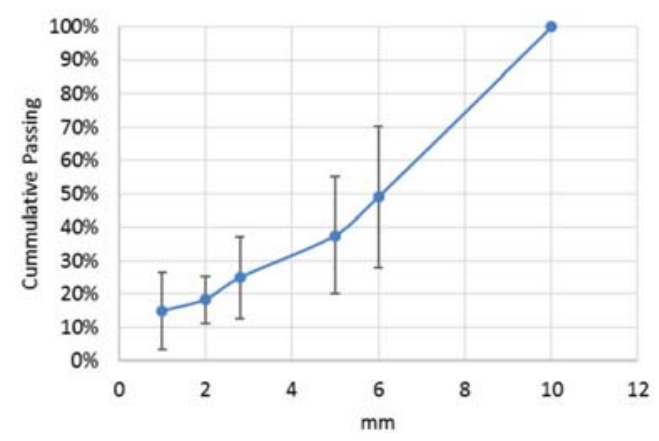

Figure 6-Average particle size distribution of granulated ferrochrome slag. Error bars show one standard deviation

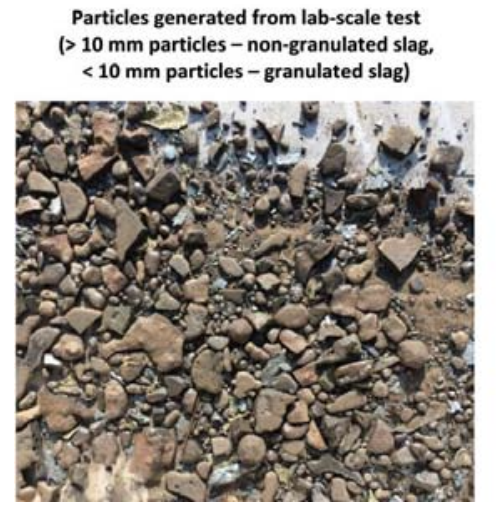

Figure 5-Solid ferrochrome slag generated in laboratory-scale air granulation trials

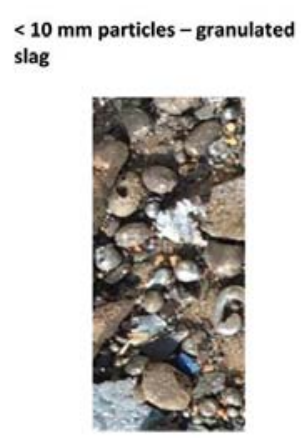




\section{Impact of air granulation on the ferrochrome value chain in metallurgical smelter complexes}

the $\mathrm{Cr}(\mathrm{VI})$ concentration in the granulated slag without causing oxidation of $\mathrm{Cr}(\mathrm{III})$ to $\mathrm{Cr}(\mathrm{VI})$ during sample preparation - which is a known concern in $\mathrm{Cr}(\mathrm{VI})$ analysis (Glastonbury, 2010). Oxidation of $\mathrm{Cr}$ (III) during sample preparation causes the true $\mathrm{Cr}(\mathrm{VI})$ content of the sample to be overestimated, which can lead to erroneous conclusions, potentially curtailing commercial applications of the tested material.

\section{Future work}

To address the limitations of slag superheat and poor flow control, a larger pilot-scale system is recommended as the next step in the development of air granulation for ferrochrome slag. Hatch has developed a larger scale, pilot version of the air granulation system which allows for a $300 \mathrm{~kg}$ sample to be fed to the granulation chamber, as shown in Figure 7. This system allows the contents of $1 \mathrm{t}$ slag ladles to be processed, or can be retrofitted downstream of the skimmer block to process slag directly from the taphole launder. The latter is recommended to ensure that sufficient heat is retained in the slag prior to granulation testing, and to enable a pilot campaign that closely reflects the eventual full-scale implementation. The larger pilot-scale system also allows for larger quantities of granulated material to be collected and tested in the metal recovery plant and/or studied for marketability.

\section{Conclusions}

Air granulation technology offers an improved way of handling ferroalloy slag compared with slow cooling and water granulation. The advantages offered by air granulation include a lower operating cost, reduced environmental footprint (including reduced water consumption), potential to improve alloy liberation, and potential for slag heat recovery. It is believed that these advantages will justify investment in further development and future transfer of this technology to the ferroalloy industry. Air granulation technology has been fully commercialized in the steel sector, and adoption by the ferroalloy sector demands a diligent approach to thoroughly verify its technical and economic feasibility. Preliminary results from small-scale test work demonstrate that air granulation is technically feasible for ferrochrome slag processing. Detailed analysis of the granulated product is still ongoing, with intentions for further testing at a larger pilotscale and determination of commercial applications for granulated ferroalloy slag.

\section{References}

BERGQUIST, J. 1912. Process of disintegrating molten slag. US patent 1047370. 17 December 1912.

Fuji, H., Tanaka, K., Nakamura, M., OKuno, R., Hashizume, S., Katayama, H., and FujITA, T. 1982. Apparatus for heat recovery from molten slag. US patent 4350326A. 21 September 1982

GLASTONBURY, R.I. 2010. Cr(VI) generation during sample preparation of solid samples -A chromite ore case study. Water SA, vol. 36, no. 1. pp. $105-110$.

HоoYKAS, C.W.J. 1979. A process and apparatus for recovering energy from molten slag. European patent 0023727 B1. 3 August 1979.

KAKOGAWA, H.F. 1982. Apparatus for heat recovery from molten slag. US patent, 4350326. 21 September 1982.

KoBE, R.O., KAKOgaWA, H.F., and TOYADA, K. 1978. Recovery of heat from molten slag from metallurgical processes. US patent 4111159 A. 5 September 1978.

Kotaro, I., Masahiко, M., and TomoYUKI, O. 1979. Method for recovering heat from molten slag and an apparatus therefor. US patent 4147332 A. 3 April 1979.

LegiLle, E. and METZ, P. 1979. Mechanical disintegration. US patent 4153440A. 8 May 1979.

MacKenzie, P.A. and HoRvat, D.T. 1999. Process and apparatus for making expanded slag. US patent 5944861. 31 August 1999.

Maruoka, N., Mizuochi, T., Purwanto, H., and Aкivama, T. 2004. Feasibility study for recovering waste heat in the steel making industry using a chemical recuperator. ISIJ International, vol. 44, no. 2. pp. 257-262.

McDonaLD, I. 2013. World Intellectual Property Organization patent 2013029935A1. 7 March 2013.

MetZ, P., Schockmel, R., and Mersch, R. 1982. Method of making slag sand and slag wool. US patent 4352764.5 October 1982. ARBED SA

Mizuoshi, T. and AкiYama, T. 2003. Cold experiments of rotary vaned-disks and wheels for slag atomization. ISIJ International, vol. 43, no. 209. pp. 1469-1471.

ORLANDER, M., Cotsworth, R.P., and MacKenzie, P. 1984. Apparatus for the pelletization of heat-liquifiable solid materials. US patent 4451221. 24 May 1984.

Pickering, S., Hay, N., Roylance, T., and Thomas, G. 1985. New process for dry granulation and heat recovery from molten blast furnace slag. Ironmaking and Steelmaking, vol. 12, no. 1. pp. 14-20.

Rodd, L., Koehler, T., WALKER, C., and Voermann, N. 2010. Economics of slag heat recovery from ferronickel slags. Proceedings of the 49th Annual Conference of Metallurgists (COM2010), Vancouver. Canadian Institute of Mining, Metallurgy and Petroleum, Montreal. pp. 1-12.

Zhang, H., Wang, H., Zhu, X., QiU, Y.-J., Li, K., Chen, R., and Liao, Q. 2013. A review of waste heat recovery technologies towards molten slag in steel industry. Applied Energy, vol. 112. pp. 956-966.

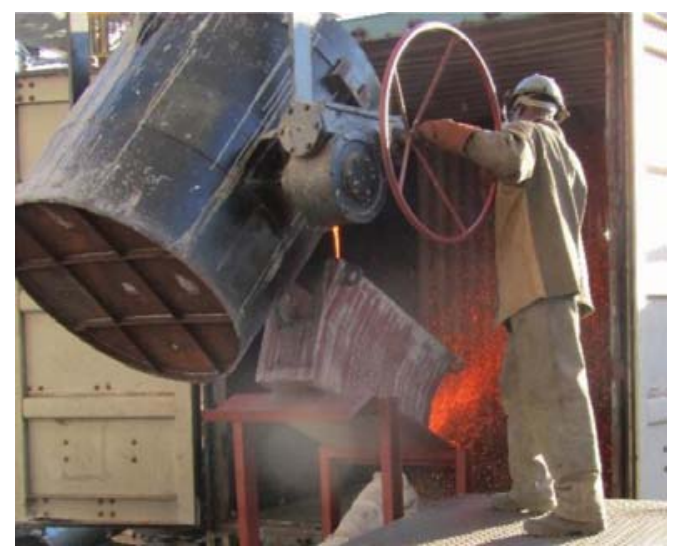

Figure 7-Pilot-scale air granulation system 